\title{
Rendimento de cortes comerciais e composição tecidual da carcaça de cabritos mestiços
}

\author{
Antonia Lucivânia de Sousa Monte ${ }^{1}$, Arturo Bernardo Selaive-Villarroel ${ }^{2}$, Juan Ramón \\ Olalquiaga Pérez ${ }^{3}$, Jorge Fernando Fuentes Zapata ${ }^{4}$, Frederico José Beserra ${ }^{5}$, Antonio \\ Nunes de Oliveira ${ }^{6}$
}

\footnotetext{
${ }^{1}$ Faculdade de Tecnologia CENTEC - Sobral.

${ }^{2}$ Depto. de Zootecnia/UFC.

${ }^{3}$ Depto. de Zootecnia/UFLA.

${ }^{4}$ Depto. de Tecnologia de Alimentos/UFC.

${ }^{5}$ Universidade de Fortaleza.

${ }^{6}$ Doutorando em Zootecnia.
}

RESUMO - A composição relativa dos cortes comerciais da carcaça e a composição tecidual (músculo, osso e gordura) da perna, do lombo e da paleta de cabritos mestiços Boer e Anglo-nubiano foram analisadas em 20 cabritos de dois grupos genéticos diferentes (13 1/2 Anglo-nubiano $\times \frac{1}{2} 2$ sem raça definida, SRD e $7 \frac{1}{2} 2$ Boer $\times 1 \frac{1}{2}$ SRD). Os animais foram abatidos aos 10 meses de idade, com $29 \pm 0,08 \mathrm{~kg}$ peso corporal. Após resfriamento $\left(2^{\circ} \mathrm{C}\right)$ da carcaça por 24 horas, as carcaças foram separadas nos cortes: perna, lombo (anterior e posterior), paleta, peito, costela, pescoço e fraldinha para determinação dos rendimentos em relação ao peso da carcaça fria. Em seguida, a perna, o lombo (anterior e posterior) e a paleta foram dissecados em tecidos muscular, adiposo e ósseo para estimação das relações músculo:osso (RMO) e músculo:gordura (RMG). Os rendimentos médios dos cortes foram: $30,8 \%$ de perna, $25,1 \%$ de lombo (17,9\% no anterior e 7,0\% no posterior), 22,0\% de paleta, 4,8\% de peito, $6,8 \%$ de pescoço, $4,8 \%$ de costela e 5,6\% de fraldinha. Não foi observado efeito entre os grupos genéticos para os rendimentos dos cortes, exceto o rendimento de costela, que foi superior nos cabritos Anglo-nubiano $\times$ SRD (5,12\%) em comparação aos Boer $\times$ SRD (4,49\%). Nos cabritos Boer $\times$ SRD, os rendimentos de tecido muscular (61,05\%), as relações RMO (3,91) e RMG $(6,85)$ foram superiores, enquanto, nos cabritos Anglo-nubiano $\times$ SRD, os rendimentos foram superiores para os tecidos adiposo $(10,23 \%)$ e ósseo $(16,79 \%)$. A carcaça dos cabritos Boer $\times$ SRD apresenta maior proporção de tecido muscular nos cortes de maior valor comercial em comparação à de cabritos Anglo-nubiano $\times$ SRD.

Palavras-chave: tecido adiposo, tecido muscular, músculo:gordura, músculo:osso

\section{Commercial cut and tissue yields in carcasses from crossbred kid goats}

\begin{abstract}
Carcass composition related to commercial cuts and tissue composition (muscle, bone and fat) from leg, loin and shoulder of kid goats crossbred Anglo-Nubian or Boer were evaluated in 20 kids from two different genetic groups (13 $1 \frac{1}{2}$ Anglo-Nubian $\times 1 \frac{1}{2}$ Undefined Breed - UB and 7 1/2 Boer $\times 1 / 2$ UB). The animals were slaughtered at 10 months of age and average body weight of $29 \mathrm{~kg} \pm 0.08$. After 24 hours of cooling $\left(2^{\circ} \mathrm{C}\right)$, the carcasses were separated in the cuts: leg, loin (fore loin and rear loin), shoulder, breast, rib, neck and flank for the determination of yields related to cold carcass weight. After that, leg, loin (fore loin and rear loin )and shoulder were dissected in muscle, fat and bone tissues to estimate muscle:bone (MBR) and muscle:fat (MFR) ratios. The average yields for the cuts were: $30.8 \%$ of leg, $25.1 \%$ of loin (17.9\% fore loin and $7.0 \%$ rear loin), $22.0 \%$ of shoulder, $4.8 \%$ of breast, $6.9 \%$ of neck, $4.8 \%$ of rib, and $5.6 \%$ of flank. No significant effect of genetic groups on cut yields was detected, except for the rib, that was higher for Anglo-Nubian $\times$ UB (5.12\%) than for Boer $\times$ UB (4.49\%). \%). In Boer $\times$ UB kids, muscle tissue yield (61.05\%), MBR (3.91) and MFR (6.85) were higher, while for Anglo-Nubian $\times$ UB yield were higher for fat (10.23\%) and bone (16.79\%) tissues. The carcass from crossbred Boer $\times$ UB kids showed higher muscle tissue in the cuts of major commercial value than that from Anglo-Nubian $\times$ UB kids.
\end{abstract}

Key Words: adipose tissue, lean:bone, lean:fat, lean tissue

\section{Introdução}

A composição de cortes e a composição tecidual são aspectos que influenciam diretamente a qualidade da carcaça.
A composição de cortes baseia-se no desmembramento da carcaça em peças menores, de forma a permitir melhor comercialização, enquanto a composição tecidual se baseia na quantidade de tecido muscular, adiposo e ósseo da carcaça. 
A composição relativa, ou proporção dos diferentes cortes da carcaça, é um dos principais fatores relacionados à qualidade da carcaça. Para o consumidor, a composição dos cortes em porcentagem de músculo, gordura e osso é o critério mais importante para sua avaliação do maior ou menor custo da carne. Desse modo, o valor dos animais com aptidão para produção de carne é determinado pela composição tecidual relativa de sua carcaça e seu conhecimento constitui fator importante para determinar a qualidade da carcaça (Huidobro \& Cañeque, 1994).

A influência do genótipo sobre os componentes do peso vivo depende da diferença de maturidade entre as raças (Yamamoto et al., 2004). De acordo com a aptidão da raça, podem ser encontrados diferentes valores para a composição da carcaça e a influência de alguns componentes do peso vivo diminui à medida que a raça se especializa para a produção de carne (Mendonça et al., 2003).

Entre as raças exóticas com aptidão para produção de carne, a Boer se destaca por apresentar carcaça de qualidade superior às demais raças caprinas e pela boa distribuição de massa muscular, além da menor deposição de gordura subcutânea não apenas nos cortes de 1a categoria, mas também na paleta, corte considerado de $2^{\mathrm{a}}$ categoria. A raça Boer possui a capacidade de transmitir aos descendentes suas características de produtor de carne, podendo constituir-se boa alternativa para cruzamentos com outras raças e/ou tipos raciais criados no Brasil (Erasmus, 2000).

O conhecimento da composição corporal, do ponto de vista econômico, pode contribuir para determinar com maior precisão o peso mais adequado de abate, em cada grupo genético, e favorecer a máxima valorização do produto.

O cruzamento de uma raça de baixo potencial para produção de carne com raças especializadas para este propósito é uma alternativa para melhorar o rendimento da carcaça e obter cortes com adequada proporção de músculos, ossos e gordura. O músculo é o tecido mais valorizado na carcaça de animais de corte, nos quais o osso praticamente não tem valor. A relação entre os pesos destes tecidos é, portanto, uma característica de importância econômica.

Os cortes de maior valor comercial das carcaças caprinas são a perna, o lombo (dianteiro e traseiro) e a paleta. A qualidade da carcaça depende da quantidade de tecidos componentes, principalmente o muscular, ósseo e adiposo (Delfa et al., 1992; Zapata et al., 2001).

No Nordeste, as carcaças caprinas são comercializadas inteiras ou em meias-carcaças, o que contribui para que poucos trabalhos sejam realizados para estudo do rendimento de cortes e da qualidade da carcaça de cabritos. Com a importância da carne caprina no mercado consumidor nordestino e nacional, tornam-se necessárias maiores e melhores informações sobre rendimento e qualidade de carcaça visando subsidiar a cadeia produtora da carne caprina brasileira.

Este trabalho foi realizado com o objetivo de avaliar a qualidade da carcaça de cabritos mestiços $1 / 2$ Anglo-nubiano $\times 1 / 2$ SRD e $1 / 2$ Boer $\times$ SRD por meio do rendimento dos cortes comerciais e da composição tecidual da perna, do lombo e da paleta.

\section{Material e Métodos}

Foram avaliadas as carcaças de 20 cabritos mestiços resultantes de cruzamentos de bodes das raças Boer e Anglo-nubiano com cabras Sem Raça Definida (SRD): 13 1 12 Anglo-nubiano $\times 1 \frac{1}{2}$ SRD e $71 \frac{1}{2}$ Boer $\times 1 \frac{1}{2}$ SRD.

Os animais receberam aleitamento natural pela mãe, concentrado e feno de leucena como volumoso. Após o desmame, foram mantidos em regime de semiconfinamento em pastagem nativa melhorada e foram recolhidos ao centro de manejo no final da tarde, onde receberam suplementação alimentar à base de milho, farelo de soja, farelo de trigo, uréia e sal comum $(65,6 ; 10,0 ; 19,0 ; 1,0$ e $0,5 \%$, respectivamente) e água à vontade. Durante o período de terminação em confinamento (60 dias antes do abate), os animais foram alimentados com ração composta de $70 \%$ de concentrado com 6\% PB e 75\% de NDT e 30\% de volumoso à base de feno de capim-elefante e leucena.

Os animais foram abatidos aos 10 meses de idade com peso corporal médio de $29 \mathrm{~kg}$, esfolados e eviscerados. As carcaças foram envolvidas em sacos de polietileno e mantidas por 24 horas em temperatura de 2 a $4^{\circ} \mathrm{C}$ para obtenção do peso da carcaça fria. Após a retirada do pescoço, a carcaça foi dividida em duas partes simétricas por meio de corte longitudinal da coluna vertebral. A meiacarcaça esquerda foi dividida em seis cortes comerciais (perna, lombo anterior e posterior, paleta, peito, costela e fraldinha), os quais foram pesados e congelados para análises posteriores.

Os limites anatômicos entre os cortes foram feitos seguindo a anatomia da espécie caprina descrita por Getty (1986). O corte do lombo anterior (da 1aa à última vértebra torácica) foi delimitado pela parte dorsal da região do costado, englobando aproximadamente $7 \mathrm{~cm}$ de costela. A base óssea do lombo posterior compreendeu da primeira à última vértebra lombar, onde foram realizados dois cortes: um entre a última vértebra torácica e a primeira lombar e outro entre a última lombar e a primeira sacral (Figura 1).

A perna e o lombo (anterior e posterior) foram considerados cortes de primeira, a paleta, corte de segunda (Yamamoto et al., 2004; Garcia et al., 2004) e os demais 


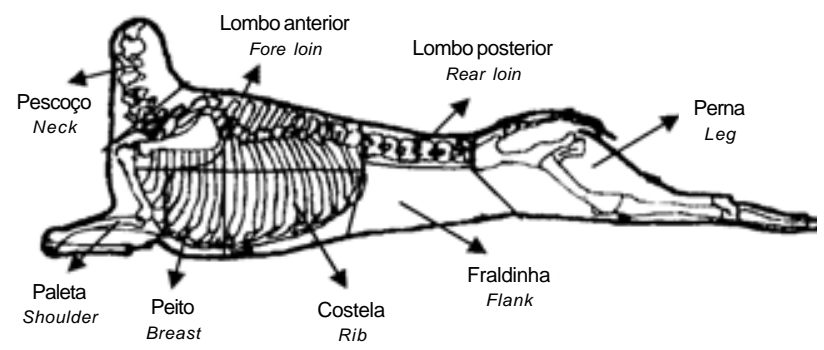

Figura 1 - Cortes da carcaça de cabrito.

Figure 1 - Cuts of kid goat carcass.

cortes, de terceira categoria. O rendimento dos cortes foi estimado em relação ao peso da meia-carcaça fria. Para o cálculo do rendimento do pescoço, o peso desse corte foi dividido por dois.

Os cortes perna, paleta e lombo anterior e posterior foram congelados e, imediatamente antes da dissecação, foram descongelados durante 24 horas em câmara de refrigeração com temperatura de $2 \mathrm{a} 4^{\circ} \mathrm{C}$. Imediatamente após a dissecação, realizada segundo metodologia adotada por Santos (2001), procedeu-se à pesagem dos tecidos (muscular, adiposo, ósseo e outros). O rendimento percentual dos tecidos de cada corte foi tomado em relação ao peso do próprio corte imediatamente antes da dissecação para estimação das relações músculo:osso e músculo:gordura.

Os dados dos grupos experimentais foram analisados pelo procedimento GLM do pacote estatístico do SAS (1998) e as médias comparadas pelo teste Tukey.

\section{Resultados e Discussão}

Os cortes considerados de primeira (Tabela 1) representaram $55,8 \%$ do total da meia-carcaça fria, enquanto os dos cortes de segunda corresponderam a $21,9 \%$ e os dos cortes de terceira, 22,1\%. Esses valores diferem dos encontrados por Sen et al (2004) em cortes equivalentes de caprinos nativos da Índia abatidos aos $28 \mathrm{~kg}$ de PV. Esses autores descreveram valores de 42,0\% para os cortes de primeira, 26,2,0\% para os de segunda e 32,0\% para os de terceira.

O grupo genético não afetou $(\mathrm{P}>0,05)$ o rendimento da perna, que representou em média 30,7\% do total da carcaça fria, semelhante ao observado por Pérez et al. (2001), em cabritos Crioulo (29\%), e ao encontrado por Sen et al. (2004), em corte equivalentes de caprinos nativos da Índia (28,2\%). Esperava-se que o rendimento da perna dos cabritos Boer $\times$ SRD fosse superior ao dos cabritos Anglo-nubiano $\times$ SRD, em virtude da melhor conformação do posterior dos animais da raça Boer (Malan, 2000). O rendimento da perna apresentou baixa correlação, porém
Tabela 1 - Peso da carcaça $(\mathrm{kg})$ e rendimentos médios (\%) de cortes comerciais de cabritos mestiços Anglo-nubiano e Boer com SRD

Table 1 - Carcass weight ( $\mathrm{kg}$ ) and average yield (\%) of commercial cuts of kid goats crossbred Anglo-Nubian and Boer with SRD

\begin{tabular}{|c|c|c|c|}
\hline \multirow[t]{2}{*}{$\begin{array}{l}\text { Peso/Rendiment } \\
\text { Weight/Yield }\end{array}$} & \multicolumn{2}{|c|}{$\begin{array}{l}\text { Grupo genético* } \\
\text { Genetic group }\end{array}$} & \multirow[t]{2}{*}{$\begin{array}{l}\text { Média geral } \\
\text { Overall mean }\end{array}$} \\
\hline & \multicolumn{2}{|c|}{ nglo-nubiano $\times$ SRD Boer $\times$ SRD } & \\
\hline $\begin{array}{l}\text { Peso de carcaça } \\
\text { Carcass weight }\end{array}$ & $14,1 \pm 1,66^{\mathrm{a}}$ & $13,0 \pm 0,81^{a}$ & $13,6 \pm 0,60$ \\
\hline $\begin{array}{l}\text { Perna } \\
\text { Leg } \\
\text { Lombo } \\
\text { Loin }\end{array}$ & $30,8 \pm 0,97^{a}$ & $30,7 \pm 0,96^{a}$ & $30,7 \pm 0,35$ \\
\hline $\begin{array}{l}\text { Total } \\
\text { Loin }\end{array}$ & $24,7 \pm 1,37^{a}$ & $25,4 \pm 1,69^{a}$ & $25,0 \pm 1,49$ \\
\hline $\begin{array}{l}\text { Posterior } \\
\text { Rear loin }\end{array}$ & $6,9 \pm 0,91^{\mathrm{a}}$ & $7,2 \pm 0,78^{\mathrm{a}}$ & $7,1 \pm 0,86$ \\
\hline $\begin{array}{l}\text { Anterior } \\
\text { Fore loin }\end{array}$ & $17,7 \pm 1,49^{a}$ & $18,1 \pm 1,15^{\mathrm{a}}$ & $17,9 \pm 1,37$ \\
\hline $\begin{array}{l}\text { Paleta } \\
\text { Shoulder }\end{array}$ & $21,7 \pm 0,83^{\mathrm{a}}$ & $22,2 \pm 0,45^{\mathrm{a}}$ & $21,9 \pm 0,35$ \\
\hline $\begin{array}{l}\text { Peito } \\
\text { Breast }\end{array}$ & $4,8 \pm 0,58^{a}$ & $4,7 \pm 0,53^{\mathrm{a}}$ & $4,8 \pm 0,18$ \\
\hline $\begin{array}{l}\text { Pescoço } \\
\text { Neck }\end{array}$ & $7,1 \pm 0,86^{\mathrm{a}}$ & $6,5 \pm 0,58^{a}$ & $6,8 \pm 0,42$ \\
\hline $\begin{array}{l}\text { Fraldinha } \\
\text { Flank }\end{array}$ & $5,6 \pm 0,56^{\mathrm{a}}$ & $5,6 \pm 0,47^{\mathrm{a}}$ & $5,6 \pm 0,01$ \\
\hline $\begin{array}{l}\text { Costela } \\
\text { Rib }\end{array}$ & $5,1 \pm 0,59^{a}$ & $4,4 \pm 0,52^{\mathrm{b}}$ & $4,8 \pm 0,44$ \\
\hline
\end{tabular}

Médias seguidas de letras diferentes na mesma linha diferem $(P<0,05)$ pelo teste Tukey.

Means with different letters within a row differ $(P<0.05)$ by Tukey test.

$(\mathrm{P}<0,05)$ positiva (Tabela 2), com os rendimentos de lombo anterior e costela.

O lombo e a paleta representaram $25,0 \%$ (anterior com $17,9 \%$ e posterior com $7,1 \%$ ) e $21,9 \%$, respectivamente, enquanto os rendimentos de peito, pescoço e fraldinha foram de 4,8; 6,8 e 5,6\%, respectivamente, e não diferiram $(\mathrm{P}>0,05)$ entre os grupos genéticos estudados (Tabela 1$)$. Rendimentos semelhantes foram verificados por Todaro et al. (2002) para paleta (20,3\%) e lombo posterior (6,0\%) de cabritos procedentes da Sicília. Esperava-se que o rendimento do lombo dos cabritos Anglo-nubiano $\times$ SRD fosse superior ao dos animais Boer $\times$ SRD, uma vez que os mestiços Anglo-nubiano apresentaram carcaça mais alongada, no entanto, esta diferença não foi observada.

O rendimento do lombo posterior (Tabela 2) apresentou baixa correlação, mas positiva, com o rendimento de paleta $(0,54)$, de fraldinha $(0,53)$ e de costela $(0,49)$. Apresentou também correlação baixa, mas negativa, com os rendimentos de peito $(-0,52)$ e pescoço $(-0,50)$.

Pérez et al. (2001) obtiveram valor superior ao deste trabalho no corte do pescoço $(11,2 \%)$ de cabritos nativos do Chile. O rendimento de costela foi em média 4,8\% e foi 
Tabela 2 - Coeficientes de correlação entre os rendimentos dos cortes comerciais de cabritos mestiços Anglo-nubiano e Boer com SRD Table 2 - Correlation coefficients among yield of commercial cut of kid goats crossbred Anglo-Nubian and Boer with SRD

\begin{tabular}{lccccccc}
\hline & \multicolumn{9}{c}{ Rendimento dos cortes } \\
Cut yield
\end{tabular}

* $(\mathrm{P}<0,05), \mathrm{ns}=$ não-significativo $($ not significant)

$\mathrm{PMCF}=$ peso meia-carcaça fria (half carcass cold weight), RPA = rendimento da paleta (shoulder yield), RPE = rendimento da perna (leg yield), RLP = rendimento do lombo posterior (rear loin yield), RLA = rendimento do lombo anterior (fore loin yield), RCO = rendimento da costela (rib yield), RPT = rendimento do peito (breas yield), RPC = rendimento do pescoço (neck yield), RFR = rendimento da fraldinha (flank yield).

maior $(\mathrm{P}<0,05)$ nos cabritos mestiços Anglo-nubiano $(5,1 \%)$. Maior rendimento destes cortes em qualquer um dos grupos genéticos estudados não é desejável, pois o valor comercial desses cortes é inferior ao dos demais cortes.

Houve efeito $(\mathrm{P}<0,05)$ do grupo genético no rendimento da maioria dos tecidos estudados nos diferentes cortes da carcaça (Tabela 3). Dos tecidos avaliados, o de maior expressividade foi o muscular em ambos os grupos genéticos (tecido de maior importância alimentar), com média de $61,3 \%$ em relação ao total dos cortes, enquanto o ósseo e o adiposo perfizeram $24,9 \%$ no total.

Em pesquisa com cabritos Boer puros no sul da África, Tshabalala et al. (2003) estudaram regiões anatômicas equivalentes às avaliadas neste trabalho e encontraram rendimento superior de tecido muscular $(74,1 \%)$ em comparação aos observados neste estudo com mestiços Boer. A superioridade dos cabritos Boer africanos provavelmente está relacionada ao fato de serem animais puros e se encontrarem em sua região de origem, onde puderam expressar todo o potencial produtivo. A maior quantidade de tecido muscular nos diferentes cortes da carcaça descrita nos cabritos mestiços Boer (Dhanda et al., 2003) foi confirmada neste trabalho, de modo que os mestiços Boer (61,9\%) apresentaram rendimento superior aos mestiços Anglo-nubiano (60,7\%).

Na perna, o rendimento de tecido muscular apresentou valor médio de $65,5 \%$ (Tabela 3 ) e não diferiu $(\mathrm{P}>0,05)$ entre os grupos genéticos, com valores semelhantes aos relatados por Gallo et al. (1996), em caprinos nativos do Chile (66,2\%). Dhanda et al. (2003) observaram rendimento superior em caprinos mestiços Boer $\times$ Angorá (70,0\%) e mestiços Boer $\times$ Saanen (68,5\%). Nos valores descritos por esses autores, os animais mestiços Boer apresentaram melhor potencial genético para produção de tecido muscular na perna em comparação aos deste trabalho.
Em comparação ao corte de lombo (anterior e posterior), o tecido muscular foi maior $(\mathrm{P}<0,05)$ nos cabritos mestiços Boer (Tabela 3), com valores semelhantes aos verificados por Sen et al. (2004), em caprinos nativos da Índia (62,0\%), e superiores aos observados por Gallo et al. (1996), em caprinos nativos do Chile (53,5\%). A maior quantidade de tecido muscular no lombo dos cabritos mestiços Boer confirma a observação visual de grande desenvolvimento lombar da raça Boer.

Na paleta, o grupo genético não teve efeito $(\mathrm{P}>0,05)$ no rendimento de tecido muscular e apresentou valor médio de $62,2 \%$. Esse rendimento foi superior ao obtido por Dhanda et al. (2003) em cabritos mestiços Boer na Austrália (67,5\%) e semelhante ao verificado por Gallo et al. (1996), em caprinos nativos do Chile (61,9\%). O rendimento do tecido muscular (RTM) apresentou alta $(\mathrm{P}<0,01)$ correlação positiva (Tabela 4) com a relação músculo:gordura (RMG) da perna $(0,86)$, do lombo posterior $(0,91)$ e anterior $(0,92)$ e ainda com a relação músculo:osso (RMO) da perna $(0,72)$ e do lombo posterior $(0,92)$ e anterior $(0,90)$.

Correlações negativas $(\mathrm{P}<0,05)$ foram observadas entre os rendimentos dos tecidos muscular e adiposo (Tabela 4), com valores de $-0,55$ para a paleta, $-0,78$ para a perna, -0,90 para o lombo anterior e -0,87 para o lombo posterior. O tecido adiposo representou em média 9,2\% do total do rendimento dos tecidos nos cortes estudados e foi maior no lombo anterior $(12,6 \%)$ e menor na perna $(7,8 \%)$ (Tabela 3). Rendimento semelhante foi relatado por Dhanda et al. (2003) na perna (7,0 a 8,7\%) de cabritos mestiços Boer na Austrália. Os cabritos mestiços Anglo-nubiano apresentaram maior quantidade $(\mathrm{P}<0,05)$ de tecido adiposo em comparação aos mestiços Boer nos cortes do lombo posterior e da paleta (Tabela 3). Entretanto, não foi observada diferença para porcentagem de tecido adiposo $(\mathrm{P}>0,05)$ 
entre os grupos genéticos nos cortes da perna e do lombo anterior.

Dos totais dos tecidos, o rendimento médio ósseo foi de $15,7 \%$ e foi menor $(\mathrm{P}<0,05)$ nos cabritos mestiços Boer, o que reflete a característica de maior produção de carne da raça Boer, com maior proporção de tecido muscular e menor de tecido ósseo. Em cortes equivalentes, Sen et al. (2004) observaram em caprinos nativos da Índia valor similar aos deste trabalho $(16,6 \%)$ para o rendimento de tecido ósseo.

O grupo genético influenciou $(\mathrm{P}<0,05)$ o rendimento do tecido ósseo do corte do lombo (anterior e posterior) e foi maior nos cabritos mestiços Anglo-nubiano. O corte paleta, no entanto, não apresentou diferença $(\mathrm{P}>0,05)$ (Tabela 3).

Observou-se alta correlação negativa em todos os cortes entre o rendimento de tecido adiposo e a relação músculo:gordura da paleta, da perna e do lombo anterior e posterior (Tabela 4). No entanto, o rendimento do tecido ósseo apresentou alta correlação negativa $(\mathrm{P}<0,01)$ com a relação músculo:osso da paleta, da perna e do lombo anterior e posterior.

Nos cortes de maior valor comercial, a relação média músculo:osso (RMO) dos cabritos mestiços foi de 3,94:1,0 e não diferiu entre os grupos genéticos estudados (Figura 2). Em cortes semelhantes, proporções equivalentes foram verificadas por Pralomkarn et al. (1995), em mestiços Anglonubiano (4,11:1,0), e por Mahgoub et al. (2005), em cabritos árabes $(3,47: 1,0)$.

A relação músculo:osso nos cabritos mestiços Boer foi melhor $(\mathrm{P}<0,05)$ nos cortes de lombo (anterior e posterior) e pior no corte da perna que os cabritos mestiços Anglonubiano (Figura 2a). A menor quantidade de tecido ósseo dos cabritos mestiços Boer no lombo (anterior e posterior) e dos cabritos mestiços Anglo-nubiano na perna (Tabela 3) influenciaram positivamente a relação músculo:osso.

A razão média músculo:gordura (RMG) dos cortes analisados dos cabritos mestiços de Anglo-nubiano e mestiços de Boer foi de 7,10:1,0 e foi maior $(\mathrm{P}<0,05)$ nos cabritos mestiços Boer (7,40:1,0) (Figura 2b). Os animais mestiços em estudo apresentaram maior quantidade de tecido muscular em relação aos cabritos árabes estudados por Mahgoub et al. (2005), que apresentaram, em cortes equivalentes aos deste estudo relação músculo:gordura de 4,11:1,0.

Entre os cortes analisados, a perna apresentou a maior relação músculo:gordura $(8,36: 1,0)$ e o lombo anterior, a menor (4,66:1,0) (Figura 2b). Houve efeito significativo do grupo genético sobre a relação músculo:gordura dos cortes do lombo posterior e da paleta, que foi superior $(\mathrm{P}<0,05)$ nos cabritos mestiços Boer em relação aos mestiços Anglonubiano. Estes dados indicam que os cabritos mestiços 
Tabela 4 - Coeficientes de correlação entre os rendimentos dos cortes e tecidos de cabritos mestiços Anglo-nubiano e Boer com SRD

Table 4 - Correlation coefficients of commercial cuts and tissue yields of kid goats crossbred Anglo-Nubian and Boer with SRD

Paleta

Shoulder

\begin{tabular}{lcccccc}
\hline & RC & RTM & RTO & RTA & RMO & RMG \\
& $C Y$ & $L T Y$ & $B T Y$ & $F T Y$ & $L B R$ & $L F R$ \\
\hline RC $(C Y)$ & - & $-0,33^{\mathrm{ns}}$ & $0,06^{\mathrm{ns}}$ & $-0,02^{\mathrm{ns}}$ & $-0,14^{\mathrm{ns}}$ & $-0,01^{\mathrm{ns}}$ \\
RTM (LTY) & & - & $-0,17^{\mathrm{ns}}$ & $-0,55^{*}$ & $0,43^{*}$ & $0,60^{*}$ \\
RTO (BTY) & & - & $0,22^{\mathrm{ns}}$ & $-0,96^{* *}$ & $-0,22^{\mathrm{ns}}$ \\
RTA (FTY) & & & - & $-0,35^{\mathrm{ns}}$ & $-0,99^{* *}$ \\
RMO (LBR) & & & & - & $0,37^{\mathrm{ns}}$ \\
\hline
\end{tabular}

Perna

Leg

\begin{tabular}{lccccc}
\hline RC (CY) & $-0,01^{\mathrm{ns}}$ & $0,08^{\mathrm{ns}}$ & $-0,10^{\mathrm{ns}}$ & $-0,05^{\mathrm{ns}}$ & $0,08^{\mathrm{ns}}$ \\
RTM (LTY) & - & $-0,53^{*}$ & $-0,78^{*}$ & $0,72^{* *}$ & $0,86^{* *}$ \\
RTO (BTY) & & - & $0,08^{\mathrm{ns}}$ & $-0,96^{* *}$ & $-0,20^{\mathrm{ns}}$ \\
RTA (FTY) & & & - & $-0,25^{\mathrm{ns}}$ & $-0,98^{* *}$ \\
RMO (LBR) & & & & - & $0,40^{\mathrm{ns}}$ \\
\hline
\end{tabular}

Lombo posterior

Rear loin

\begin{tabular}{|c|c|c|c|c|c|c|}
\hline $\mathrm{RC}(\mathrm{CY})$ & - & $0,02^{\mathrm{ns}}$ & $-0,17^{\mathrm{ns}}$ & $-0,11^{\mathrm{ns}}$ & $0,14^{\mathrm{ns}}$ & $0,13^{\mathrm{ns}}$ \\
\hline RTM (LTY) & & - & $-0,88^{* *}$ & $-0,90^{* *}$ & $0,92^{* *}$ & $0,91^{* *}$ \\
\hline RTO (BTY) & & & - & $0,84^{* *}$ & $-0,99^{* *}$ & $-0,85^{* *}$ \\
\hline RTA (FTY) & & & & - & $-0,87^{* *}$ & $-0,99^{* *}$ \\
\hline RMO (LBR) & & & & & - & $0,88^{* *}$ \\
\hline
\end{tabular}

Lombo anterior

Fore loin

\begin{tabular}{lccccc}
\hline RC (CY) & $-0,15^{\mathrm{ns}}$ & $0,15^{\mathrm{ns}}$ & $0,15^{\mathrm{ns}}$ & $-0,15^{\mathrm{ns}}$ & $-0,17^{\mathrm{ns}}$ \\
RTM (LTY) & - & $-0,80^{* *}$ & $-0,87^{* *}$ & $0,90^{* *}$ & $0,92^{* *}$ \\
RTO (BTY) & & - & $0,69^{*}$ & $-0,98^{* *}$ & $-0,73^{*}$ \\
RTA (FTY) & & & - & $-0,75^{*}$ & $-0,99^{* *}$ \\
RMO (LBR) & & & & - & $0,80^{*}$
\end{tabular}

* $(P<0,05) ; * *(P<0,01) ;$ ns = não-significativo (not significant).

$\mathrm{RC}=$ rendimento corte (cut yield), $\mathrm{RTM}=$ rendimento do tecido muscular (lean tissue yield), RTO = rendimento do tecido ósseo (bone tissue yield), RTA = rendimento do tecido adiposo (fat tissue yield), RMO = relação músculo osso (lean:bone ratio), RMG = relação músculo gordura (lean:fat ratio).

Boer possuem maior quantidade de tecido muscular no lombo posterior e na paleta em comparação aos mestiços Anglo-nubiano. Não houve efeito $(\mathrm{P}>0,05)$ do grupo genético na relação músculo:gordura dos cortes da perna e do lombo anterior.

Do ponto de vista da qualidade da carne, a relação músculo:gordura pode ser considerada a mais importante, pois a presença de gordura tem grande importância na aceitação da carne, pois influencia nas características de textura, suculência e sabor. No âmbito econômico, a relação músculo:osso é a mais importante, pois constitui indicativo da proporção do tecido de consumo humano. $\mathrm{O}$ fato de os cabritos mestiços Anglo-nubiano apresentarem menor RMG nos cortes comerciais analisados pode ser um indício de que a carne desses animais tem qualidade superior à dos cabritos mestiços Boer.

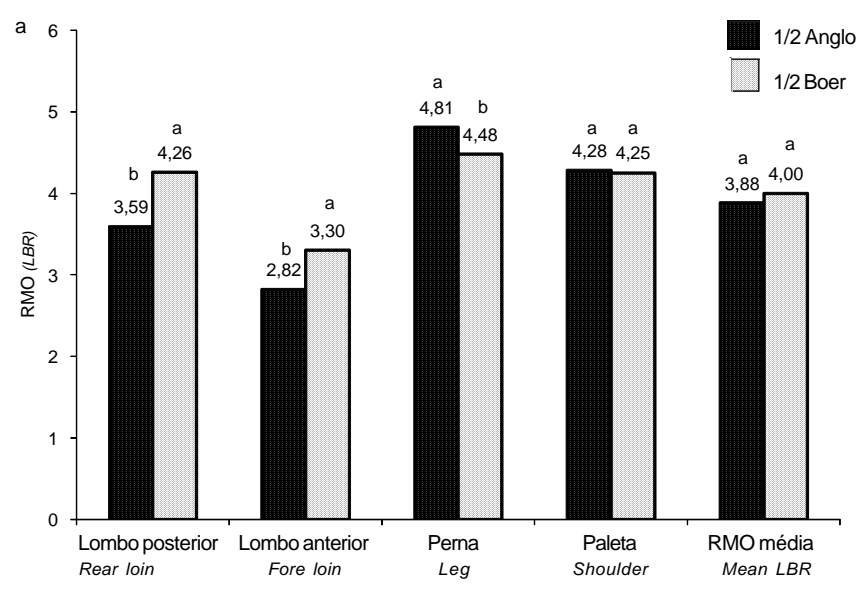

b

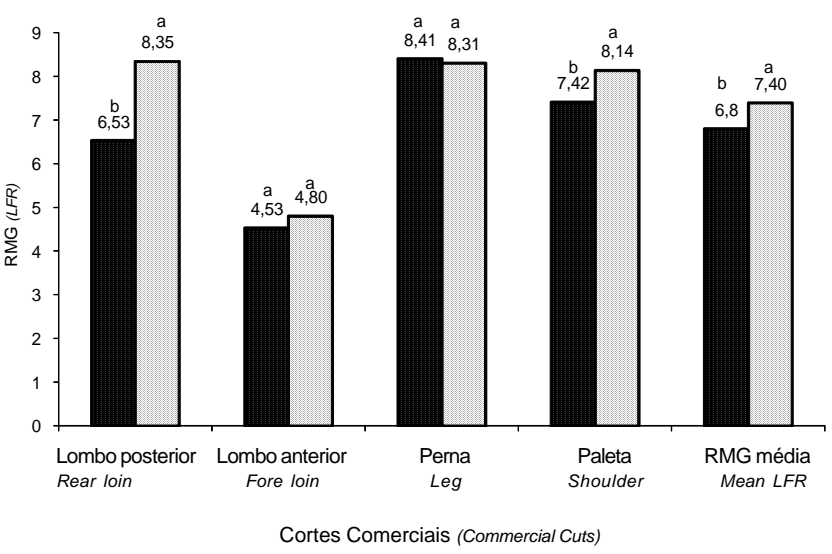

Figura 2 - Razão músculo:osso - RMO (a) e músculo:gordura RMG (b) dos cortes comerciais de cabritos mestiços Anglo-nubiano e Boer com SRD.

Figure 2 - Lean:bone ratio - LBR (a) and lean:fat ratio - LFR (b) in commercial cuts of kid goats crossbred Anglo-Nubian and Boer with SRD.

Médias seguidas de letras diferentes na mesma linha diferem $(\mathrm{P}<0,05)$ pelo teste Tukey.

Means with different letters within the same line differ $(P<0.05)$ among them by Tukey test.

\section{Conclusões}

Cabritos mestiços resultantes do cruzamento de reprodutores das raças Boer e Anglo-nubiano com matrizes SRD não diferem significativamente quanto ao rendimento da maioria dos cortes comerciais. Carcaças de cabritos mestiços Boer apresentaram maior rendimento de tecido muscular, enquanto a dos mestiços Anglo-nubiano, maior rendimento dos tecidos adiposo e ósseo.

Os cabritos mestiços Anglo-nubiano apresentaram menor relação músculo:gordura nos cortes comerciais. Os cortes de primeira representam mais de 55,0\% da carcaça dos cabritos mestiços estudados. 


\section{Literatura Citada}

DELFA, R.; TEIXEIRA, A.; GONZALEZ, Y.C. Composición de la canal. Medida de la composición. Ovis, n.23, p.9-22, 1992.

DHANDA, J.S.; TAYLOR, D.G.; MURRAY, M.J. Part 2. Carcass composition and fatty acids profiles of adipose tissue of male goat: effects of genotype and liveweight at slaughter. Small Ruminant Research, v.50, p.67-74, 2003.

ERASMUS, J.A. Adaptations to vários environments and redistence to disease of the improved Boer goat. Small Ruminant Research, v.36, p.179-187, 2000.

GALLO, C; BRETON, Y.L.; WAINNRIGHT, I. et al. Body and carcass composition of male and female Criollo goats in the South of Chile. Small Ruminant Research, v.23, p.163$169,1996$.

GARCIA, I.F.F.; PÉREZ, J.R.O.; BONAGURIO, S. et al. Estudo dos cortes da carcaça de cordeiros Santa Inês puros e cruza Santa Inês com Texel, Ile de France e Bergamácia. Revista Brasileira de Zootecnia, v.33, n.2, p.453-462, 2004.

GETTY, R. Anatomia dos animais domésticos. Rio de Janeiro: Guanabara, 1986. v.1, 1134p.

HUIDOBRO, F.R.; CAÑEQUE, V. Produción de carne em corderos de raza Manchega. IV. Ecuaciones predictorias de la composición tisular de las canales. Investigación Agropecuaria Produción Sanidad Animal, v.9, n.1, p.71-81, 1994.

MALAN, S.W. The improved Boer goat. Small Ruminant Research, v.36, p.65-170, 2000.

MAHGOUB, O; KADIM, N.M; AL-SAQRY, N.M. et al. Potential of Omamni Jebel Akhdar goat for meat production under feedlot condition. Small Ruminant Research, v.56, p.223230, 2005.

MENDONÇA, G.; OSÓRIO, J.C; OLIVEIRA, N.M. et al. Morfologia, características da carcaça e componentes do peso vivo em borregos Corriedale e Ideal. Ciência Rural, v.33, n.2, p.351355, 2003.
PÉREZ, P.; MAINO, M.; MORALES, M.S. et al. Effects of goat milk and milk substitutes and sex on productive parameters and carcass composition of Creole kid. Small Ruminant Research, v.42, p.87-93, 2001.

PRALOMKARN, W.; SAITHANOO, S.; KOCHAPAKDEE, S. et al. Effects of genotype and plane of nutrition on carcass characteristics of Thai native and Anglo-Nubian x Thai native male goats. Small Ruminant Research, v.16, p.21-25, 1995

STATISTICAL ANALYSIS SYSTEM - SAS. User's guide: statistics. Cary: 1998. 956p.

SANTOS, C.L.; PÉREZ, J.R.O.; MUNIZ, J.A. et al. Desenvolvimento relativo dos tecidos ósseo, muscular e adiposo dos cortes da carcaça de cordeiros Santa Inês. Revista Brasileira de Zootecnia, v.30, n.2, p.487-492. 2001.

SEN, A.R.; SANTRA, A.; KARIM, S.A. Carcass yield, composition and meat quality attributes of sheep and goats under semiarid condition. Meat Science, n.66, p.757-763, 2004.

TODARO, M.; CORRAO, A.; BARONE, C.M.A. et al. The influence of age at slaughter and litter size on some quality traits of kid meat. Small Ruminant Research, v.44, p.75-80, 2002.

TSHABALALA, P.A.; STYDOM, P.E.; WEBB, E.C. et al. Meat quality of designated South African indigenous goats and sheep breeds. Meat Science, n.65, p.563-570, 2003.

YAMOMOTO, S.M.; MACEDO, F.A.F.; MEXIA, A.A. et al. Rendimentos dos cortes e não-componentes das carcaças de cordeiros terminados com dietas contendo diferentes fontes de óleo vegetal. Ciência Rural, v.34, n.6, p.45-52, 2004.

ZAPATA, J.F.F; SEABRA, L.A.J.; NOGUEIRA, C.M. et al. Características de carcaça de pequenos ruminantes no Nordeste do Brasil. Ciência Animal, v.11, n.2, p.79-86, 2001. 